\title{
Molecular characterization of a novel picobirnavirus in a chicken
}

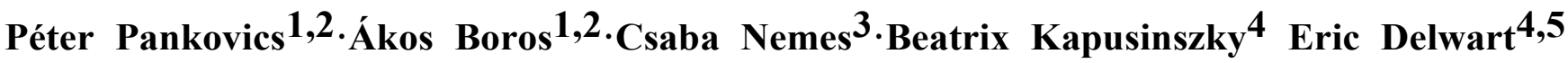 Gábor Reuter ${ }^{1,2}$}

Gábor Reuter reuter.gabor@gmail.com

1 Regional Laboratory of Virology, National Reference Laboratory of Gastroenteric Viruses, ÁNTSZ Regional Institute of State Public Health Service, Pécs, Hungary

2 Department of Medical Microbiology and Immunology, Medical School, University of Pécs, Szigeti út 12. Pécs 7624, Hungary

3 Veterinary Diagnostic Directorate of the Central Agricultural Office, Kaposvár, Hungary

4 Blood Systems Research Institute, San Francisco, CA, USA

5 University of California, San Francisco, CA, USA

\begin{abstract}
Picobirnaviruses (PBVs) are bisegmented viruses with a wide geographical and host species distribution. The number of novel PBV sequences has been increasing with the help of the viral metagenomics. A novel picobirnavirus strain, pbv/ CHK/M3841/HUN/2011, was identified by viral metagenomics; the complete segment 1 (MH327933) and 2 (MH327934) sequences were obtained by RT-PCR from a cloacal sample of a diseased broiler breeder pullet in Hungary. Although the conserved nucleotide (e.g., ribosome binding site) and amino acid motifs (e.g., ExxRxNxxxE, Sdomain of the viral capsid and motifs in the RNA-dependent RNA polymerase) were identifiable in the chicken picobirnavirus genome, the putative segment 1 showed low $(<30 \%)$ amino acid sequence identity to the corresponding proteins of marmot and dromedary PBVs, while segment 2 showed higher $(<70 \%)$ amino acid sequence identity to a wolf PBV protein sequence. This is the first full-genome picobirnavirus sequence from a broiler breeder chicken, but the pathogenicity of this virus is still questionable.
\end{abstract}

The GenBank[/EMBL/DDBJ] accession number for the study sequence: MH327933, MH327934. 
Since 1988, when the first picobirnaviruses (PBVs) were dis- covered [1,2], many different novel PBVs have been identified [1, 3-22]. PBVs are bisegmented, double-stranded (ds) RNA viruses belonging to the family Picobirnaviridae. Segment 1 encodes two hypothetical proteins (ORF1 and ORF2) with unknown function and a viral capsid protein (ORF3) [23]. Segment 2 encodes the RNAdependent RNA polymerase (RdRp, ORF1) [8]. Due to the segmented nature of the PBV genome, the process of reassortment is also observed [15]. PBVs are thought to be able to coinfect vertebrates and have been associated with watery diarrhoea, gastroenteritis outbreaks, and sporadic cases of disease. They are potential opportunistic pathogens with a wide geographic distribution [23]. However, the presence of ShineDalgarno-like sequences in recently described PBV genomes may suggest a prokaryotic host origin [24, 25].

In this study, the first complete genome sequence of a novel PBV from a cloacal sample of a broiler breeder pullet in Hungary is presented.

The diseased 18-week old broiler breeder chicken was part of a broiler breeder chicken colony in which the number of dead animals suddenly increased. Hepato-renopathy and liver rupture were found by routine pathohistological investigation, suggesting a toxic origin rather than an infectious pathogen. Known bacterial pathogens could not be isolated. Total RNA was extracted from a cloacal sample by the TRIzol method. The complete genome of pbv/CHK/ M3841/HUN/2011 (MH327933, MH327934) was identified by viral metagenomics [26, 27] and amplified by adapter- ligated RT-PCR [4].

Segments 1 and 2 are 2532 nt and 1700 nt long, respectively (Fig. 1). The conserved GUAAA and ACUGC nt sequences are identifiable in the 5' and 3' ends of segments 1 and 2, respectively. Segment 1 contains three open reading frames, with ORF1 and ORF2 encoding two hypothetical proteins with unknown function, whereas ORF3 encodes the viral capsid protein (VCP). The conserved motif of the ribosomal binding site (RBS) nucleotide sequence (AGG AGG) is present upstream of the ORF2 and ORF3 AUG start codon [28]. Three-copies of the conserved $\operatorname{Exx} \mathbf{R x} \mathbf{N x x x E}$ aa motif and the conserved aa motifs of the VCP S-domain are identifiable in ORF2 and ORF3, respectively [29, 30] (Fig. 1). The ORF2 and ORF3 aa sequences showed $27 \%$ and $30 \%$ identity to the corresponding proteins of marmot (KY928777) and dromedary (KM573793) PBVs, respectively, but no significant hits were found in the case of ORF1 using Blast(p). Segment 2 contains an ORF1 encoding the viral RdRp gene [8]. Interestingly, the ORF starts with the alternative start codon UUG instead of AUG, and an optimal RBS was found upstream with a spacing of 7 nucleotides, (Fig. 1). The conserved aa motifs are also identifiable in the RdRp coding region of segment 2 (Fig. 1) [31, 32]. The RdRp shares $69 \%$ aa sequence identity with the corresponding protein of wolf PBV (KT934307). 


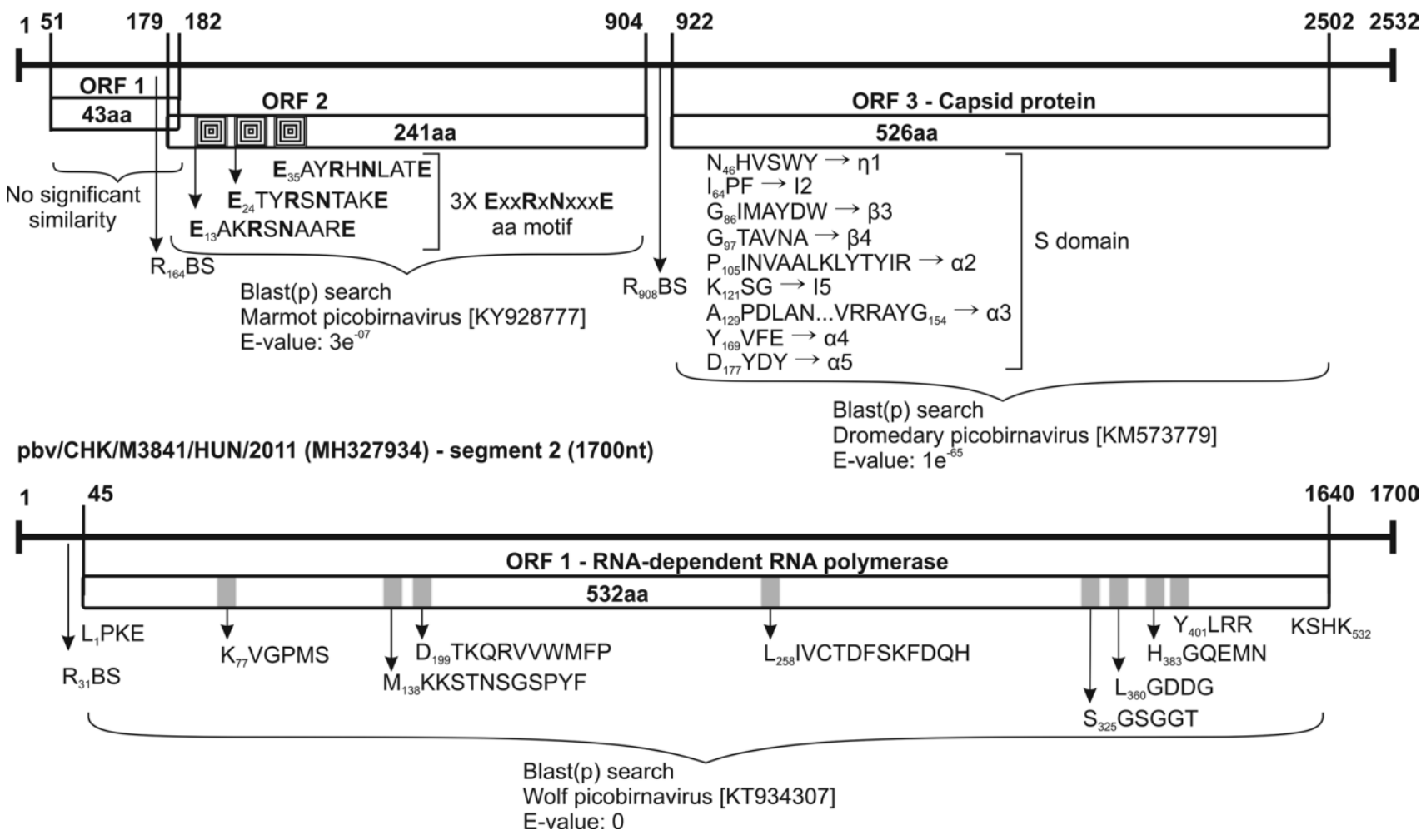

Fig. 1 Genome organization of the novel chicken picobirnavirus strain pbv/CHK/M3841/HUN/2011 from a chicken cloacal sample. Segment 1 encodes two hypothetical proteins (ORF1 and ORF2) with unknown function and the viral capsid protein (ORF3). Segment 2 encodes the viral RNA-dependent RNA polymerase (RdRp). The ribosome binding sites (RBS), the ExxRxNxxxE amino acid (aa) motifs, the conserved aa motifs of the S-domain of the capsid protein, and the conserved aa motifs of the RdRp are marked. The most significant relatives are identified based on the lowest E-scores in a Blast(p) search. The ORFs were identified using ORFfinder (NCBI, https://www.ncbi.nlm.nih.gov/orffinder/), allowing the use of "ATG" and alternative initiation codons. The conserved nucleotide sequences and amino acid motifs were identified manually using GeneDoc [33]

Phylogenetic analysis based on the deduced aa sequences VCP (segment 1) and RdRp (segment 2) of the study strain and other representative PBV showed that the novel chicken picobirnavirus strain pbv/CHK/M3841/HUN/2011 occupies a divergent phylogenetic position among PBVs (Fig. 2). 


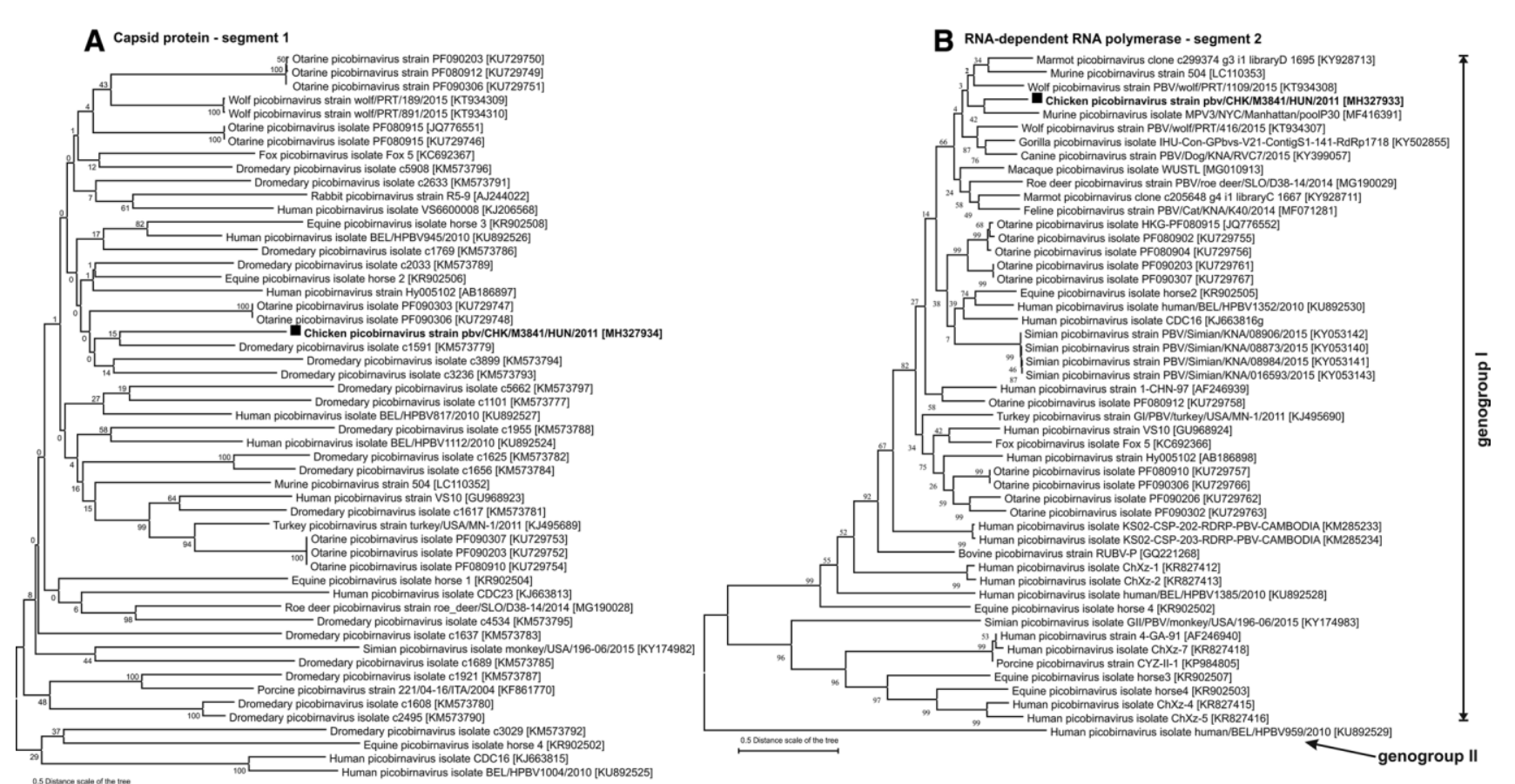

Fig. 2 Phylogenetic reconstruction of the A) viral capsid (segment 1) and B) RNA-dependent RNA polymerase (segment 2) proteins of the novel chicken picobirnavirus strain PBV/CHK/M3841/HUN/2011 (bold) and representative picobirnaviruses. The complete amino acid (aa) sequences were aligned using the MUSCLE algorithm, and the aa sequence alignment was pre-tested by the maximum-likelihood (ML) method. Phylogenetic trees were constructed in MEGA 6 [34] using the ML method based on the LeGascuel [35] with Freqs. (+F) model. A discrete gamma distribution ( + G5) was used to model evolutionary rate differences among sites and the rate variation model allowed for some sites to be evolutionarily invariable $[+\mathrm{I}]$. The tree is drawn to scale, with branch lengths measured in the number of substitutions per site.

Despite the wide distribution of PBVs, there is still no convincing evidence of their pathogenicity in vertebrates. In this study, a novel picobirnavirus was detected in a cloacal sample from a broiler breeder chicken by viral metagenomics and molecular techniques, but the role of the virus in this infection was not confirmed, and its pathogenicity is still questionable. Further experimental studies are needed to clarify the virulence or synergistic effect of PBVs in vertebrates.

Acknowledgement This study was supported by the grant from the Hungarian Scientific Research Fund (NKFIH/OTKA K111615). P.P. and Á.B. are supported by the János Bolyai Research Scholarship of the Hungarian Academy of Sciences.

\section{Compliance with ethical standards}

Funding This study was funded by Hungarian Scientific Research Fund (NKFIH/OTKA 111615). 
Conflict of interest The authors declare that they have no conflict of interest.

Ethical approval All applicable international, national, and/or institutional guidelines for the care and use of animals or animal samples were followed.

\section{References}

1. Pereira HG, Fialho AM, Flewett TH, Teixeira JMS, Andrade ZP (1988) Novel viruses in human faces. Lancet 2:103-104

2. Pereira HG, Flewett TH, Candeias JAN, Barth OM (1988) A virus with bisegmented doublestranded RNA genome in rat (Oryzomys nigriens) intestines. J Gen Virol 69:2749-2754

3. van Leeuven M, Williems MM, Koraka P, Simon JH, Smits SL, Osterhaus AD (2010) Human picobirnaviruses identified by molecular screening of diarrhea samples. J Clin Microbiol 48:1787-1794

4. Wakuda M, Pongsuwanna Y, Taniguchi K (2005) Complete nucleotide sequence of two RNA segments of human picobirnaviruses. J Virol Methods 126:165-169

5. Zhang T, Breitbart M, Lee WH, Run JQ, Cl Wei, Soh SW, Hib- berd ML, Liu ET, Rohwer F, Ruan Y (2006) RNA viral com- munity in human feces: prevalence of plant pathogenic viruses. PLoS Biol. 4:e3

6. Ng TF, Vega E, Kondov NO, Markey C, Deng X, Gregoricus N, Vinjé J, Delwart E (2014) Divergent picobirnaviruses in human feces. Genome Announc 15:e00415-14

7. Sun G, Zang Q, Gu Y, Niu G, Ding C, Zhang P (2016) Viral metagenomics analysis of picobirnavirus-positive feces children with sporadic diarrhea in China. Arch Virol 161:971-975

8. Rossen BI, Fang ZY, Glass RI, Monroe SS (2000) Cloning of human picobirnavirus genomic segments and development of an RT-PCR detection assay. Virology 277:316-329

9. Woo PC, Teng JL, Bai R, Wong AY, Martelli P, Hui SW, Tsang AK, Lau CC, Ahmed SS, Yip CC, Choi GK, Li KS, Lam CS, Lau SK, Yuen KY (2016) High diversity of genogroup I picobirnaviruses in mammals. Front Microbiol 7:1886

10. Woo PCY, Lau SKP, Bai R, Teng JLL, Lee P, Martelli P, Hui SW, Yuen KY (2012) Complete genome sequence of a novel picobirnavirus, otarine picobirnavirus, discovered in California Sea Lions. J Virol 86:6377-6378

11. Bodewes R, van der Giessen J, Haagmans BL, Osterhaus AD, Smits SL (2013) Identification of 
multiple novel viruses, including a parvovirus and a hepevirus, in feces of red foxes. $\mathrm{J}$ Virol $87: 7758-7764$

12. Verma H, Mor SK, Erber J, Goyal SM (2015) Prevalence and complete genome characterization of turkey picobirnaviruses. Infect Genet Evol 30:134-139

13. Navarro R, Yibin C, Nair R, Peda A, Aung MS, Ketzis J, Malik YS, Kobayashi N, Ghosh S (2017) Molecular characterization of complete genomic segment-2 of picobirnavirus strains detected in a cat and a dog. Infect Genet Evol 54:200-204

14. Gonzales G, Sasaki M, Burkitt-Gray L, Kamiya T, Tsuju NM, Sawa H, Ito K (2017) An optimistic protein assembly from sequence reads salvaged an uncharacterized segment of mouse picobirnavirus. Sci Rep 7:40447

15. Conceição-Neto N, Mesquita JR, Zeller M, Yinda CK, Álvares F, Roque S, Petrucci-Fonseca F, Godinho R, Heylen E, Van Ranst M, Matthijnssens J (2016) Reassortment among picobirnaviruses found in wolves. Arch Virol 161:2859-2862

16. Li L, Giannitti D, Low J, Keyes C, Ullmann LS, Deng X, Aleman M, Pesavento PA, Pusterla N, Delwart E (2015) Exploring the virome of diseased horses. J Gen Virol 96:2721-2733

17. Zhao G, Wu G, Lim ES, Droit L, Krishnamurthy S, Barouch DH, Virgin HW, Wang D (2017) VirusSeeker, a computational pipeline for virus discovery and virome composition analysis. Virology 503:21-30

18. Day JM, Ballard LL, Duke MV, Scheffler BE, Zsák L (2010) Metagenomic analysis of the turkey gut RNA virus community. Virol J 7:313

19. Symonds EM, Griffin DW, Breitbart M (2009) Eukaryotic viruses in wastewater samples from the United States. Appl Environ Microbiol 75:1402-1409

20. Malik YS, Sircar S, Dhama K, Singh R, Ghosh S, Bányai K, Vlas- ova AN, Nadia T, Singh RK (2018) Molecular epidemiology and characterization of picobirnaviruses in small ruminant populations in India. Infect Genet Evol 63:39-42

21. Duraisamy R, Akiana J, Davoust B, Mediannikov O, Michelle C, Robert C, Parra HJ, Raoult D, Biagini P, Desnues C (2018) Detection of novel RNA viruses from free-living gorillas, Republic of the Congo: genetic diversity of picobirnaviruses. Virus Genes 54:256-271

22. Kuhar U, Vengust G, Jamnikar-Ciglenecki U (2017) Complete Genome Sequence of Roe Deer Picobirnavirus Strain PBV/roe_deer/SLO/D38-14/2014. Genome Announc 5:e01329-17

23. Ganesh B, Bányai K, Martella V, Jakab F, Masachessi G, Kob- ayashi N (2012) Picobirnavirus infections: viral persistence and zoonotic potential. Rev Med Virol 22:245-256

24. Krishnamurthy SR, Wang D (2018) Extensive conservation of prokaryotic ribosomal binding sites 
in known and novel picobirnaviruses. Virology 516:108-114

25. Stanssens P, Remaut E, Fiers W (1985) Alterations upstream from the Shine-Dalgarno region and their effect on bacterial gene expression. Gene 36:211-223

26. Victoria JG, Kapoor A, Li L, Blinkova O, Slikas B, Wang C, Naeem A, Zaidi S, Delwart E (2009) Metagenomic analysis of viruses in stool samples from children with acute flaccid paralysis. J Virol $83: 4642-4651$

27. Kapoor A, Victoria J, Simmonds P, Slikas E, Chieochansin T, Naeem A, Shaukat S, Sharif S, Alam MM, Angez M, Wang C, Shafer RW, Zaidi S, Delwart E (2008) A highly prevalent and genetically diversified Picornaviridae genus in South Asia children. Proc Natl Acad Sci USA 105:20482-20487

28. Shine J, Delgarno L (1974) The 3 'terminal sequence of Esceri- chia coli 16S ribosomal RNA: complementarity to nonsense triplets and ribosome binding sites. Proc Natl Acad Sci USA $71: 1342-1346$

29. Costa BD, Duquerroy S, Tarus B, Delmas B (2011) Picobirnaviruses encode a protein with repeats of the ExxRxNxxxE motif. Virus Res 158:251-256

30. Duquerroy S, Costa BD, Henry C, Vigouroux A, Libersou S, Lep- ault J, Navaza J, Delmas B, Rey FA (2009) The picobirnavirus crystal structure provides functional insights into virion assembly and cell entry. EMBO J 28:1655-1665

31. Collier AM, Lyytinen OL, Guo YR, Toh Y, Poramen MM, Tao YJ (2016) Initiation of RNA polymerization and polymerase encap- sidation by small dsRNA virus. PLoS Pathog 12:e1005523

32. Navarro R, Yibin C, Nair R, Peda A, Aug MS, Ketzis J, Malik YS, Kobayashi N, Ghosh S (2017) Molecular characterization of complete genomic segment-2 of picobirnavirus strains detected in a cat and a dog. Infect Genet Evol 54:200-204

33. Nicholas KB and Nicholas HBJ, 1997. GeneDoc: a tool for editing and annotating multiple sequence alignments Distributed by the author. http:/www.psc.edu/biomed/genedoc

34. Tamura K, Stecher G, Peterson D, Filipski A, Kumar S (2013) MEGA6: molecular evolutionary genetics analysis version 6.0. Mol Biol Evol 30:2725-2729

35. Le SQ, Gascuel O (1993) An improved general amino acid replacement matrix. Mol Biol Evol. 25(7):1307-1320 